Check for updates

Cite this: RSC Adv., 2019, 9, 20332

Received 10th April 2019

Accepted 13th June 2019

DOI: 10.1039/c9ra02700a

rsc.li/rsc-advances

\section{Dual-scale $\mathrm{TiO}_{2}$ and $\mathrm{SiO}_{2}$ particles in combination with a fluoroalkylsilane and polydimethylsiloxane superhydrophobic/superoleophilic coating for efficient solvent-water separation $\dagger$}

\author{
Frances L. Heale, (D) Maud Einhorn, Kristopher Page, Ivan P. Parkin (D) \\ and Claire J. Carmalt (D)*
}

Surfaces that have unique wettabilities and are simultaneously superhydrophobic with water contact angles $>150^{\circ}$, and superoleophilic with oil contact angles $<5^{\circ}$, are of critical importance in the oil/solvent-water separation field. This work details the facile preparation of highly efficient oil-water separation devices that successfully combine hierarchical surface roughening particles and low surface energy components with porous substrates. Coatings were generated using $\mathrm{TiO}_{2}$ and hydrophobic- $\mathrm{SiO}_{2}$ micro/nanoparticle loadings which were then embedded within polydimethylsiloxane, commercially known as Sylgard® 184, and $1 \mathrm{H}, 1 \mathrm{H}, 2 \mathrm{H}, 2 \mathrm{H}$-perfluorooctyltriethoxysilane (FAS) polymer mixtures. The resulting slurries were dip coated onto copper meshes with varying pore diameters (30,60 and 100 meshes had 595, 250 and 149 $\mu \mathrm{m}$ pore dimensions respectively). Functional testing proved that mesh substrates coated in the lowest Sylgard $\AA^{184}$ : FAS polymer ratio formulations displayed heightened water repellency and retained their superoleophilic properties upon repeat testing. The largest average water contact angle of $145 \pm 1^{\circ}$, was recorded on a copper 30 mesh substrate with a coating comprising $\mathrm{H}-\mathrm{SiO}_{2}$ microparticles and $\mathrm{TiO}_{2}$ nanoparticles in a 1:9 polymer mixture of Sylgard $®$ and FAS. The coating's extreme oil affinity was supported by high solvent-water separation efficiencies ( $\geq 99 \%)$ which withstood numerous testing/ washing cycles.

\section{Introduction}

The increasing volume of oil and/or solvent contamination in industrial wastewater is a lasting contribution to the deterioration of our marine and terrestrial ecosystems. The food, leather, textile and petrochemical industries all generate significant amounts of unwanted oily water during daily production. ${ }^{1}$ When these continuous waste outputs couple with freak accidents, such as oil spills, the natural environment suffers severe implications for up to one decade after each isolated event. ${ }^{2}$ During the period between 2010 and 2017 there was more than 47000 tonnes of petrochemical oil spilt in aquatic environments, $80 \%$ of this amount was lost in just ten incidents. ${ }^{3}$ It is therefore of great importance to engineer efficient oil-water separation techniques capable of rapidly cleaning the environment in the event of future spills and to decontaminate oily industrial waste.

Department of Chemistry, University College London, 20 Gordon Street, London, WC1H 0AJ, UK. E-mail: c.j.carmalt@ucl.ac.uk; Tel: +44 (0)2076797528

$\uparrow$ Electronic supplementary information (ESI) available. See DOI: 10.1039/c9ra02700a
Interactions between liquids and surfaces are central to this field of research. Superhydrophobic materials often make use of nano and/or microscale protrusions combined with very low surface energy modifications to achieve static water contact angles $\geq 150^{\circ} \cdot{ }^{4,5}$ Water droplets upon these materials can exist in a Wenzel state, whereby the droplets 'stick' to all parts of the surface, or Cassie-Baxter regime where droplets 'slip' on a lubricating air layer trapped within surface asperities. ${ }^{6,7}$ The literature details various ways of fabricating novel water repellent surfaces inspired by nature's waterproof materials such as lotus leaves butterfly wings and geckos' feet. ${ }^{5}$ Plasma enhanced chemical vapor deposition (PECVD) was carried out by Bico et al. to generate carbon flake-like multiscale surface structures. ${ }^{8}$ Aerosol-assisted chemical vapour deposition (AACVD) of Sylgard ${ }^{\circledR} 184$ or polydimethylsiloxane (PDMS) and tetraethyl orthosilicate (TEOS) afforded appropriately rough and transparent coatings on glass substrates. ${ }^{9-11}$ Alternative superhydrophobic generating methods such as chemical etching, ${ }^{\mathbf{1 2}}$ electrospinning ${ }^{\mathbf{1 3 , 1 4}}$ and lithographic imprinting/templatation ${ }^{\mathbf{1 5}}$ have enhanced the functionality of oil-water separation, selfcleaning, anti-icing and anti-corrosion materials. ${ }^{12,16-18}$

Whilst water repellency is crucial to certain oil-water separation devices, materials with two wettability regimes have been 
known to improve separation efficiency. A surface displaying both superhydrophobic 'water-hating' and superoleophilic 'oilloving' properties can be tuned for selective separation providing its surface energy resides between that of the solvent/ oil and water it aims to separate (approximately between $30 \mathrm{mN}$ $\mathrm{m}^{-1}$ and $\left.70 \mathrm{mN} \mathrm{m}{ }^{-1}\right) .{ }^{19}$ Filtration and/or absorption are successful types of oil-removing techniques that encompass both size exclusion and wettability selectivity mechanisms. Pore sizes are commonly designed to either let oil run straight through the mesh/membrane or for the material to absorb the hydrocarbon whilst water is repelled. ${ }^{20}$

Copper meshes have been etched with nitric acid and alkali $\left(\mathrm{NaOH} / \mathrm{K}_{2} \mathrm{~S}_{2} \mathrm{O}_{8}\right)$ solutions before modification with selfassembled monolayers of hexadecanethiol and dodecanethiol respectively. High water contact angles, $\sim 150^{\circ}$, and low oil contact angles, $<5^{\circ}$, produced materials that separated at least $97 \%$ of water from an oily solution. ${ }^{21,22}$ Vertically-aligned multiwalled carbon nanotubes were synthesised on a stainless steel mesh via CVD. Needle-likes tubes created a high surface area and aided capillary action; the oil contact angle was recorded at $0^{\circ}$ and oil penetrated the mesh in $0.4 \mathrm{s.}^{23} \mathrm{Li}$ et al. fabricated candle soot and silica coated meshes that repelled hot water and corrosive liquids. These coated meshes worked as effective gravity separation devices with $\sim 99 \%$ of organic solvents permeating through the device. ${ }^{24}$ Nano protrusions have also been introduced by electrochemical etching, a copper mesh was anodized in a $\mathrm{NaOH}$ solution $(1 \mathrm{M})$ to create a needle-like $\mathrm{Cu}(\mathrm{OH})_{2}$ film. The roughened substrate was then coated in a self-assembled monolayer of $1 \mathrm{H}, 1 \mathrm{H}, 2 \mathrm{H}, 2 \mathrm{H}$-perfluorooctyltriethoxysilane (FAS) to form a durable solvent/water separator. ${ }^{25}$ Spin coating metal mesh substrates with $\mathrm{ZnO}$ nanorods has been yet another effective fabrication method. ${ }^{26}$

Swapping a porous substrate for porous structures (on special materials) enhances robustness by removing the possibility for coating stripping. Tu et al. designed a micro-bead and nanofiber film created in one step by spraying onto any given substrate. The water contact angle on these surfaces was not as high as other but the cost and fabrication time were drastically reduced. ${ }^{27} \mathrm{~A}$ thermoplastic polyurethane mat, created via electrospinning, immersed in a hexadecyltrimethoxysilane (HDTMS) modified nanosilica solution also generated an efficient structured separation material. ${ }^{28}$ Several other surface modification methods such as electrostatic deposition, grafting polymerisation, spray drying and photo-initiated polymerisation have gained traction by utilising various polymers, gels and biomaterials. ${ }^{29,30}$

Herein we present an extremely facile one-pot method to fabricate highly efficient oil-water separation devices, $>99 \%$ efficiency. Combinations of hierarchical surface roughening particles and low surface energy components upon porous substrates lead to enhanced robustness and functionality when tested with a variety of common industrial solvents; this elevated device effectiveness across a substrate and solvent range has substantially advanced work in this area. Here, $\mathrm{TiO}_{2}$ and hydrophobic-SiO ${ }_{2}$ micro/nanoparticles were embedded within polydimethylsiloxane (Sylgard ${ }^{\circledR} 184$ ) and $1 \mathrm{H}, 1 \mathrm{H}, 2 \mathrm{H}, 2 \mathrm{H}^{-}$ perfluorooctyltriethoxysilane (FAS) polymer mixtures. Resulting slurries were dip coated onto copper meshes with varying pore diameters (30, 60 and 100 meshes had 595, 250 and $149 \mu \mathrm{m}$ pore dimensions respectively). Water contact angles, solvent separation efficiencies and mechanical stability were found to outperform many of the existing optimum superhydrophobic/ superoleophilic filtration surface previously documented.

\section{Experimental}

\subsection{Materials}

Anatase $\mathrm{TiO}_{2}$ particles (60-200 nm diameter), $\mathrm{SiO}_{2}$ particles (0.5-1.0 $\mu \mathrm{m}$ diameter and 5-15 $\mu \mathrm{m}$ diameter), $1 \mathrm{H}, 1 \mathrm{H}, 2 \mathrm{H}, 2 \mathrm{H}$ perfluorooctyltriethoxysilane, ethanol (reagent grade), toluene (reagent grade), hexane (reagent grade) and dichloromethane (reagent grade) were purchased from Sigma Aldrich. P25 $\mathrm{TiO}_{2}$ nanoparticles (21 nm diameter) were acquired from Degussa. Copper mesh substrates (30, 60 and 100 meshes had 595, 250 and $149 \mu \mathrm{m}$ pore dimensions respectively) were bought from Alfa Aesar and Sylgard® 184 and was acquired from Dow Corning.

\subsection{Preparation of polymer stock solutions}

Sylgard ${ }^{\circledR} 184$ curing agent and elastomer base in a 1 : 10 mass ratio (30.00 g combined mass) were dissolved in ethanol (150.00 g), Fig. 1a. The polydimethylsiloxane polymer was magnetically stirred for 2 hours. A colourless, viscous mixture was achieved.

A $1 H, 1 H, 2 H, 2 H$-perfluorooctyltriethoxysilane (FAS) solution was prepared by magnetically stirring FAS $(1.00 \mathrm{~g})$ in ethanol $(99.00 \mathrm{~g})$ for 2 hours to produce a clear/colourless solution, Fig. $1 \mathrm{~b}$.

\subsection{Pre-functionalisation of $\mathrm{SiO}_{2}$ particles $\left(\mathrm{H}-\mathrm{SiO}_{2}\right)$}

Due to the innate hydrophilicity of unrefined silica, 0.5-1.0 $\mu \mathrm{m}$ diameter $\mathrm{SiO}_{2}$ particles $(5.00 \mathrm{~g})$ and 5-15 $\mu \mathrm{m}$ diameter $\mathrm{SiO}_{2}$ particles were sonicated $(40 \mathrm{kHz})$ for $30 \mathrm{~min}$ in the fluoroalkylsilane (FAS) stock solution $(25 \mathrm{~mL})$. The cloudy mixture was oven dried at $60{ }^{\circ} \mathrm{C}$ for 2 hours to allow for complete solvent evaporation, a fine white hydrophobic-SiO ${ }_{2}\left(\mathrm{H}-\mathrm{SiO}_{2}\right)$ powder remained. The $\mathrm{TiO}_{2}$ particles did not require this prefunctionalisation step.

\subsection{Generation of functional oil-water separation meshes}

Optimised mineral systems (dual-scale $\mathrm{TiO}_{2}$ particles, dualscale hydrophobic-SiO ${ }_{2}\left(\mathrm{H}-\mathrm{SiO}_{2}\right)$ particles or mixed-scale $\mathrm{H}$ $\mathrm{SiO}_{2}$ particles with $\mathrm{TiO}_{2}$ particles) were placed into separate centrifuge tubes and combined with the Sylgard ${ }^{\circledR} 184$ and $1 \mathrm{H}, 1 \mathrm{H}, 2 \mathrm{H}, 2 \mathrm{H}$-perfluorooctyltriethoxysilane (FAS) stock solutions, Table S1. $\dagger$ All mixtures were sonicated $(40 \mathrm{kHz}$ ) for $30 \mathrm{~min}$ to form uniform suspensions. Copper 30, 60 and 100 mesh substrates $(15 \times 15 \mathrm{~cm})$ were loosely rolled and immersed in the suspensions for $2 \mathrm{~min}$ (one 30, 60 and 100 mesh per coating mixture) prior to oven drying at $60{ }^{\circ} \mathrm{C}$ for 2 hours.

For ease of reference the following particle combinations and loadings (embedded in a polymer mixture) have been abbreviated, Table 1. Optimised functional coatings have also been labelled, Table 2 . 
(a)

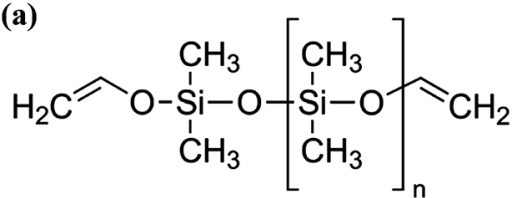

(b)<smiles>CCO[Si](CCC(F)(F)C(F)(F)C(F)(F)C(F)(F)C(F)(F)C(F)(F)F)(OCC)OCC</smiles>

Fig. 1 Structure of (a) Sylgard $\circledast 184$ polymer and (b) $1 \mathrm{H}, 1 \mathrm{H}, 2 \mathrm{H}, 2 \mathrm{H}$-perfluorooctyltriethoxysilane prior to polymerisation.

Table 1 Abbreviated labelling for particle combinations and loadings within oil-water separation coatings. Hydrophobic- $\mathrm{SiO}_{2}\left(\mathrm{H}-\mathrm{SiO}_{2}\right)$ particles were generated by functionalising the as received $\mathrm{SiO}_{2}$ mineral $(5.00 \mathrm{~g})$ in a $1 \mathrm{H}, 1 \mathrm{H}, 2 \mathrm{H}, 2 \mathrm{H}$-perfluorooctyltriethoxysilane (FAS) $(1.00 \mathrm{~g}) /$ ethanol $(99.00 \mathrm{~g})$ mixture

\begin{tabular}{|c|c|c|c|}
\hline \multirow[b]{3}{*}{ Coating label } & \multicolumn{3}{|c|}{ Particle loading/g } \\
\hline & \multicolumn{2}{|l|}{$\mathrm{TiO}_{2}$} & \multirow[b]{2}{*}{$\begin{array}{l}\mathrm{H}-\mathrm{SiO}_{2} 5-15 \\
\mu \mathrm{m}\end{array}$} \\
\hline & $21 \mathrm{~nm}$ & $\begin{array}{l}60-200 \\
\mathrm{~nm}\end{array}$ & \\
\hline A & 0.6 & - & 0.6 \\
\hline B & 0.6 & - & 0.6 \\
\hline $\mathrm{C}$ & 1.5 & 1.5 & - \\
\hline
\end{tabular}

\subsection{Characterisation}

X-ray photoelectron spectroscopy (XPS) was performed on a Thermo Scientific XPS K-Alpha X-ray Photoelectron Spectrometer with a monochromated $\mathrm{AL} \mathrm{K} \alpha \mathrm{X}$-ray source at $1486.6 \mathrm{eV}$. Fourier transform infrared (FT-IR) spectroscopy was carried out using Bruker Alpha Platinum-ATR equipment (650 to $4000 \mathrm{~cm}^{-1}$ ). Surface morphologies were investigated using a JEOL JSM-6301F scanning electron microscope (SEM) with an acceleration voltage of 5 or $10 \mathrm{kV}$.

\subsection{Functional testing}

Three water contact angles were measured per coating at ambient temperature via the sessile-drop method using a FTA 1000 optical contact angle meter $(5 \mu \mathrm{L}$ water droplet). An average value and associated error were calculated for each sample. The tilting angle, defined as the angle at which a water droplet readily slides off a slanted surface (fixed droplet volume of $0.5 \mathrm{~mL}$ ), was recorded using a digital angle finder. Averages and standard deviations were calculated.

According to the experimental setup in Fig. 2, solvent-water separation efficiencies were carried out by rapidly pouring oily mixtures over the selected separation device and recording the mass of solvent collected after $30 \mathrm{~s}$ (later converted to a percentage of the total solvent content to be separated). Three repeat readings were recorded per separation solution and the initial solvent mass present in the $10 \mathrm{~mL}$ mixture was known. One part solvent three parts water $(25 \%)$, solvent and water in equal parts $(50 \%)$ and three parts solvent one part water $(75 \%)$ mixtures of toluene-methylene blue water, hexane-methylene blue water and dichloromethane-methylene blue water (total volume, $10 \mathrm{~mL}$ ) were the chosen testing solutions.

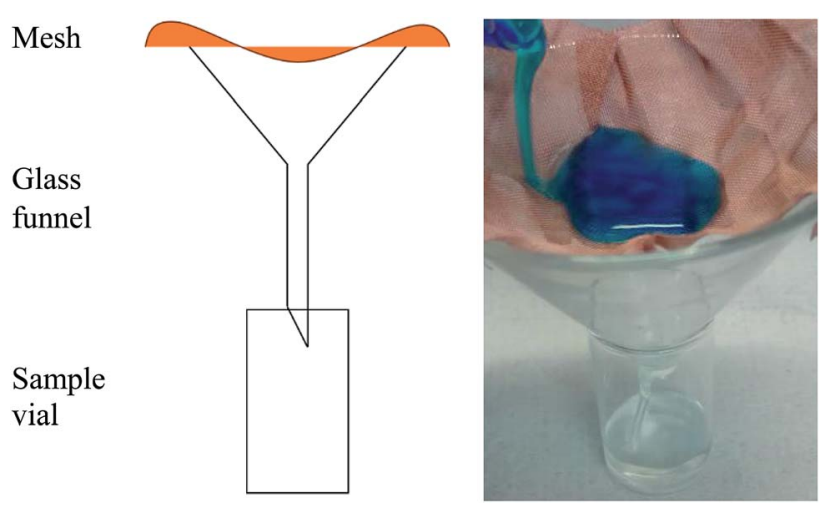

Fig. 2 Schematic and image of solvent-water separation efficiency apparatus. Mixtures of known compositions were poured onto various coated sample meshes. The mass of solvent collected after $30 \mathrm{~s}$ of separation provided relevant information for the calculation of a comparable separation efficiency percentage.

Table 2 Abbreviated labelling for particle combinations and loadings within oil-water separation coatings. $\mathrm{Hydrophobic}-\mathrm{SiO} 2\left(\mathrm{H}-\mathrm{SiO} \mathrm{O}_{2}\right)$ particles were generated by functionalising the as received $\mathrm{SiO}_{2}$ mineral $(5.00 \mathrm{~g})$ in a $1 \mathrm{H}, 1 \mathrm{H}, 2 \mathrm{H}, 2 \mathrm{H}$-perfluorooctyltriethoxysilane (FAS) (1.00 g)/ethanol $(99.00 \mathrm{~g})$ mixture

\begin{tabular}{|c|c|c|c|c|c|c|}
\hline \multirow[b]{3}{*}{ Coating label } & \multicolumn{3}{|c|}{ Particle loading/g } & \multicolumn{2}{|c|}{$\begin{array}{l}\text { Mixture of polymer stock } \\
\text { solutions/g }\end{array}$} & \multirow[b]{3}{*}{$\begin{array}{l}\text { Sylgard } \AA \\
184: \text { FAS ratio }\end{array}$} \\
\hline & \multicolumn{2}{|l|}{$\mathrm{TiO}_{2}$} & \multirow[b]{2}{*}{$\begin{array}{l}{\mathrm{H}-\mathrm{SiO}_{2}} 5-15 \\
\mu \mathrm{m}\end{array}$} & \multirow[b]{2}{*}{$\begin{array}{l}\text { Sylgard }{ }^{\circledR} \\
184\end{array}$} & \multirow[b]{2}{*}{ FAS } & \\
\hline & $21 \mathrm{~nm}$ & $\begin{array}{l}60-200 \\
\mathrm{~nm}\end{array}$ & & & & \\
\hline $\mathrm{D}$ & 0.6 & - & 0.6 & 3 & 27 & $1: 9$ \\
\hline $\mathrm{E}$ & 0.6 & - & 0.6 & 30 & - & $0: 1$ \\
\hline $\mathrm{F}$ & 1.5 & 1.5 & - & 6 & 24 & $1: 4$ \\
\hline G & 0.6 & - & 0.6 & 6 & 24 & $1: 4$ \\
\hline
\end{tabular}


Meshes were washed with ethanol ( $5 \mathrm{~mL}$ ) before and after same solvent separations and new functional meshes were used when solvents were interchanged. Methylene blue water was utilised to prove no water had permeated through the separation mesh as the blue coloured water was easily distinguished from the colourless solvent. Sample durability was further assessed using the Scotch tape test and acid and base baths: Scotch tape was firmly applied to cover the whole sample surface and then ripped/removed at speed 3 times.

\section{Results and discussion}

A one-pot synthesis was used to generate a range of highly functional 'water hating' and 'oil loving' coatings for application in oil-water separation. Various iterations of $\mathrm{TiO}_{2}$ and hydrophobic-SiO $\mathrm{S}_{2}\left(\mathrm{H}-\mathrm{SiO}_{2}\right)$ micro/nanoparticles were dispersed in Sylgard® 184 and $1 H, 1 H, 2 H, 2 H$-perfluorooctyltriethoxysilane (FAS) mixtures, as detailed in Tables $\mathrm{S} 1, \dagger \mathbf{1}$ and 2 . The resulting coatings were dip coated onto 3 types of copper meshes (30, 60 and 100 meshes had 595, 250 and $149 \mu \mathrm{m}$ pore dimensions respectively).

\subsection{Characterisation}

X-ray photoelectron spectroscopy (XPS) was carried out on the functional coatings to identify the oxidation state of Ti and chemical environments surrounding Si atoms, Fig. 3. Elemental scans of the dried optimised $\mathrm{TiO}_{2}$ particle containing coatings (D, E, F and $\mathrm{G}$ (formulations listed in Table 2)) confirmed that Ti was constantly in the +4 oxidation state; a $2 p$ doublet was characteristic of the $459.00 \mathrm{eV} \mathrm{Ti} 2 \mathrm{p}_{3 / 2}$ and the $464.70 \mathrm{eV} \mathrm{Ti} 2 \mathrm{p}_{1 / 2}$ peaks. Additionally, optimised coating formulations D, E and $\mathrm{G}$ also contained $\mathrm{SiO}_{2}$ particles. For sample D, consisting of $\mathrm{SiO}_{2}$ 5-15 $\mu \mathrm{m}$ particles $(0.6 \mathrm{~g})$ and $\mathrm{TiO}_{2} 21 \mathrm{~nm}$ particles $(0.6 \mathrm{~g})$ in a 1 : 9 polymer mixture of Sylgard ${ }^{\circledR} 184$ and FAS, the Si 2 p peak was deconvoluted into a $104.00 \mathrm{eV} \mathrm{Si}-\mathrm{O}_{2}$ and a $101.82 \mathrm{eV} \mathrm{Si-OR}$ environment. Values agreed with the literature and were consistent with other $\mathrm{TiO}_{2}$ and $\mathrm{SiO}_{2}$ particle containing samples. ${ }^{31-34}$

The X-ray diffraction pattern of coating D displays a high intensity $\mathrm{TiO}_{2}$ anatase peak at $25.4^{\circ}$ and subsequently less intense peaks at $36.7^{\circ}, 37.8^{\circ}, 38.8^{\circ}, 47.9^{\circ}, 54.6^{\circ}, 55.1^{\circ}$ and $62.5^{\circ}$. A medium intensity rutile peak was identified at $27.4^{\circ}$ and $\mathrm{SiO}_{2}$ particles were attributed to the quartz peak at $20.8^{\circ}$. As coating $\mathrm{F}$ was absent of $\mathrm{SiO}_{2}$ particles the only detectable peaks were characteristic of the anatase and rutile phases of $\mathrm{TiO}_{2}$. All coating patterns presented in Fig. $\mathrm{S} 1 \dagger$ agreed with particle standards and the Inorganic Crystal Structure Database.

Fourier transform infrared (FT-IR) analysis, consistent with the NIST Standard Reference Database, resulted in the identification of several bending and stretching modes characteristic of the Sylgard ${ }^{\circledR} 184$ and $1 H, 1 H, 2 H, 2 H$-perfluorooctyltriethoxysilane (FAS) polymer mixtures, Fig. 4. Samples containing hydrophobic-SiO ${ }_{2}\left(\mathrm{H}-\mathrm{SiO}_{2}\right)$ and/or $\mathrm{TiO}_{2}$ particles embedded in $1: 0,0: 1,1: 1,1: 4$ and $1: 9$ Sylgard ${ }^{\circledR}$ 184 : FAS ratios all had similar polymer transmittance bands. A sharp peak at $3120 \mathrm{~cm}^{-1}$ was seen in the spectra of coatings $\mathrm{D}$, $\mathrm{E}, \mathrm{F}$ and $\mathrm{G}$ which depicted the $\mathrm{C}-\mathrm{H}$ alkane stretch present in both polymers. Varying intensities of the following peaks were observed: $1257 \mathrm{~cm}^{-1}$ (sh, w) intense out of phase vinyl ether stretch in Sylgard ${ }^{\circledR} 184,{ }^{35} 1010 \mathrm{~cm}^{-1}$ (s) Si-OR Sylgard® 184 and FAS stretch, $790 \mathrm{~cm}^{-1}(\mathrm{~m})$ alkene out of plane bending in Syl$\operatorname{gard}{ }^{\circledR} 184,622 \mathrm{~cm}^{-1}$ (w) C-F FAS stretch and $457 \mathrm{~cm}^{-1}$ (w) antisymmetric $\mathrm{Si}-\left(\mathrm{CH}_{3}\right)$ Sylgard $® 184$ stretch. ${ }^{35}$ The presence of these C-F FAS stretches were synonymous with functional effectiveness; fluorine's extreme electronegativity made it only weakly susceptible to fleeting dipoles that form the basis of van der Waals forces. Consequently, the samples' fluorinated carbon chains had small intermolecular forces and therefore the low surface energy hydrophobic requirement.

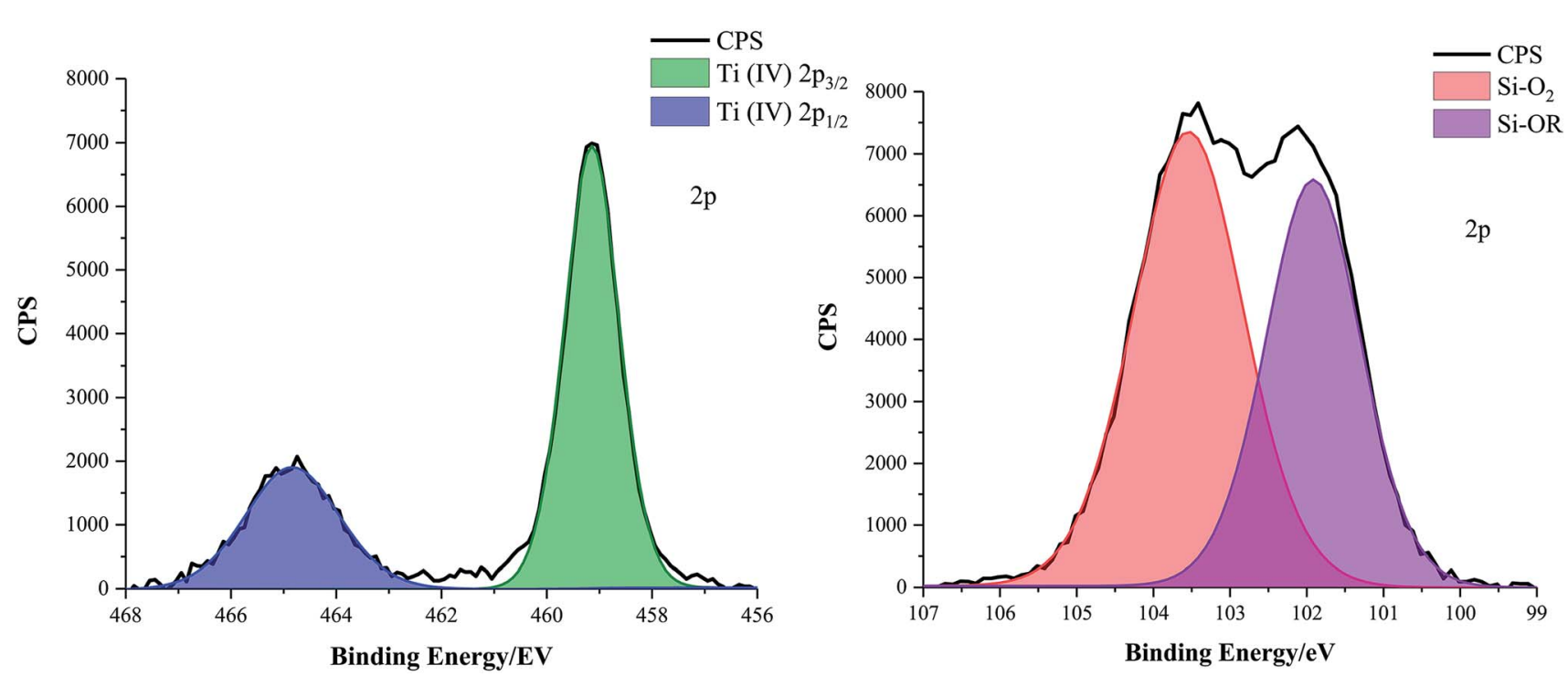

Fig. 3 Deconvoluted X-ray photoelectron spectroscopy (XPS) Ti $2 p$ and Si $2 p$ scans of coating D comprising $\mathrm{SiO}_{2} 5-15 \mu \mathrm{m}$ particles $(0.6 \mathrm{~g})$ and $\mathrm{TiO}_{2} 21 \mathrm{~nm}$ particles $(0.6 \mathrm{~g})$ in a $1: 9$ polymer mixture of Sylgard® 184 and FAS. 


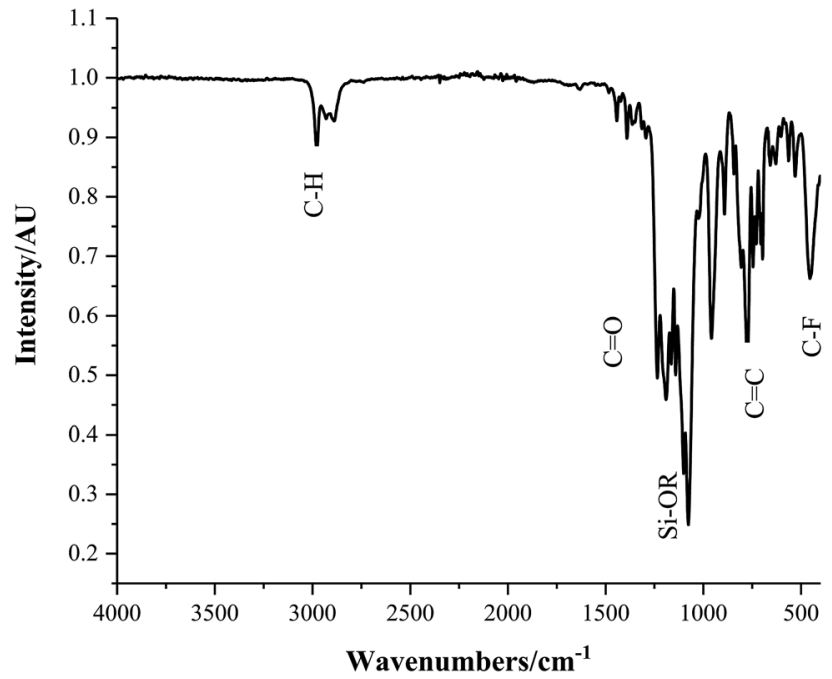

Fig. 4 Fourier transform infrared (FT-IR) spectrum of coating $\mathrm{D} ; \mathrm{SiO}_{2}$ 5-15 $\mu \mathrm{m}$ particles $(0.6 \mathrm{~g})$ and $\mathrm{TiO}_{2} 21 \mathrm{~nm}$ particles $(0.6 \mathrm{~g})$ in a $1: 9$ polymer mixture of Sylgard $® 184$ and FAS.

Scanning electron microscopy (SEM) images provided visual information about the topography of separation materials, particle size/distribution and the extent of copper mesh substrate pore blockage. This qualitative evidence was attributed to water contact angle measurements as well as separation efficiency results. Initial trial coatings containing $\mathrm{TiO}_{2}$ particles in high ratios of Sylgard ${ }^{\circledR} 184$ to FAS $(1: 1$ or $1: 0)$ resulted in almost complete pore blockage, Fig. S2. $\dagger$ As expected, pore obstruction physically impeded the passage of any solvent through the membrane and resulted in poor separation efficiencies $<25 \%$. Coatings with higher proportions of the more viscous Sylgard ${ }^{\circledR} 184$ polymer were also seen to reduce the prominence of particle roughening structures thus had reduced average water contact angle values, $<110^{\circ}$.

Fig. 5a presents SEM images of the unobstructed pores of a 30 mesh (595 $\mu \mathrm{m}$ pore dimension) copper substrate functionalised with coating $\mathrm{D}\left(\mathrm{SiO}_{2}{ }^{5}-15 \mu \mathrm{m}\right.$ particles $(0.6 \mathrm{~g})$ with $\mathrm{TiO}_{2} 21 \mathrm{~nm}$ particles $(0.6 \mathrm{~g})$ in a $1: 9$ polymer mixture of Sylgard $\circledast 184$ and FAS). Dual scale surface structures were accentuated in this coating due to the reduced quantity of Sylgard® 184 and were reflected in the high average water contact angle, $145 \pm 1^{\circ}$. However, solvent-water separation testing indicated that the pores were too large to selectively filter solvents from water and so the use of copper 30 mesh substrates were discontinued. Fig. $5 \mathrm{~b}$ displays a section of coating $\mathrm{D}$ adhered to a copper 60 mesh substrate $(250 \mu \mathrm{m}$ pore dimension). Once again, imaging proved that pore openings were clear. The average water contact angle remained relatively high, $\sim 135^{\circ}$, and the toluene-water separation efficiency in equal parts was recorded as $100 \%$. Fig. $5 \mathrm{c}$ shows images of coating $\mathrm{E}\left(\mathrm{SiO}_{2} \mathrm{5}-15\right.$ $\mu \mathrm{m}$ particles $(0.6 \mathrm{~g})$ with $\mathrm{TiO}_{2} 21 \mathrm{~nm}$ particles $(0.6 \mathrm{~g})$ in a $0: 1$ polymer mixture of Sylgard ${ }^{\circledR} 184$ and FAS) on copper 100 mesh substrates (149 $\mu \mathrm{m}$ pore dimensions). Open pore structures were conserved, due to the absence of Sylgard ${ }^{\circledR} 184$, and there was a clear presence of protruding micro and nanoscale particles. The associated average water contact angle and toluene-water separation efficiency in equal parts were $147 \pm 1^{\circ}$ and $99 \pm 1 \%$ respectively. Lastly, Fig. 5 d displays coating $\mathrm{F}$ on a copper 100 mesh substrate $\left(\mathrm{TiO}_{2} 60-200 \mathrm{~nm}\right.$ particles $(1.5 \mathrm{~g})$ with $\mathrm{TiO}_{2} 21 \mathrm{~nm}$ particles $(1.5 \mathrm{~g})$ in a $1: 4$ polymer mixture of Sylgard ${ }^{\circledR} 184$ and FAS). The small pores were $\sim 50 \%$ blocked by this polymer mixture making this an unsuitable solvent-water separation device despite preserving dual scale surface contours, average water contact angle of $146 \pm 1^{\circ}$. SEM analysis lead to the assumption that coatings with high proportions of the non-viscous fluorinated FAS polymer mixture created highly structured surface topographies and maximised the appropriate pore area of copper 60 mesh (and in some cases copper 100 mesh) substrates. This in turn elevated the average contact angle values and enhanced efficiency of solvent separation; low Sylgard ${ }^{\circledR} 184$ levels were tolerated to preserve device coating robustness.

\subsection{Functional testing}

Average water contact angle results are plotted in Fig. 6 to demonstrate the impact of changing particle loading/ combination and polymer mixture on hydrophobicity. The highly durable, viscous and adhesive Sylgard $® 184$ polymer had to be delicately balanced with the easily abraded, non-viscous and highly water repellent fluoroalkylsilane (FAS) polymer to achieve a formulation that wouldn't compromise membrane pore size (for effective solvent-water separation) but maintain functionality and durability. Coatings were prepared with $1: 0$, $0: 1,1: 1,1: 4$ and $1: 9$ Sylgard ${ }^{\circledR} 184:$ FAS polymer ratios with embedded hydrophobic- $\mathrm{SiO}_{2}\left(\mathrm{H}-\mathrm{SiO}_{2}\right)$ and/or $\mathrm{TiO}_{2}$ loading combinations and functionally contrasted. With the majority of polymer combinations dual scale $\mathrm{H}-\mathrm{SiO}_{2}$ particles produced the lowest average water contact angle values, for example $125 \pm 10^{\circ}$ was obtained with the $0: 1$ Sylgard ${ }^{\circledR} 184$ : FAS polymer ratio mixture. Dual scale $\mathrm{TiO}_{2}$ particles consistently generated the highest average water contact angle results for each coating composition (with the exception of the Sylgard ${ }^{\circledR} 184:$ FAS ratio of $1: 0$ ), a maximum of $151 \pm 7^{\circ}$ was achieved with the $1: 9$ Sylgard ${ }^{\circledR} 184$ : FAS polymer mixture. The coatings that contained the highest concentration of Sylgard ${ }^{\circledR} 184$ often performed comparatively worse than mesh coatings with a larger FAS content. These findings were expected, the abundance of -C-F polymer bonds in FAS is known to effectively reduce a material's surface energy and consequently increase the average water contact angle value. All samples were in the Cassie-Baxter regime, assumed from low tilting angle results, and improved upon the hydrophobicity of separation meshes detailed in the literature. Fore example. Xue's group generated a superhydrophilic mesh whilst Zhang's coated mesh afforded average water contact angles $<130^{\circ} .^{36,37}$

Average percentage of toluene separated from $25 \%, 50 \%$ and $75 \%$ toluene solutions $(75 \%, 50 \%$ and $25 \%$ water respectively) were contrasted on coated 60 mesh copper substrates, via the setup in Fig. S3. $\dagger$ The $\mathrm{H}-\mathrm{SiO}_{2}$ and $\mathrm{TiO}_{2}$ particle combination, B, embedded in a 1 to 9 Sylgard ${ }^{\circledR} 184$ : FAS mixture was the most effective at separating $25 \%$ toluene- $50 \%$ water solutions on 


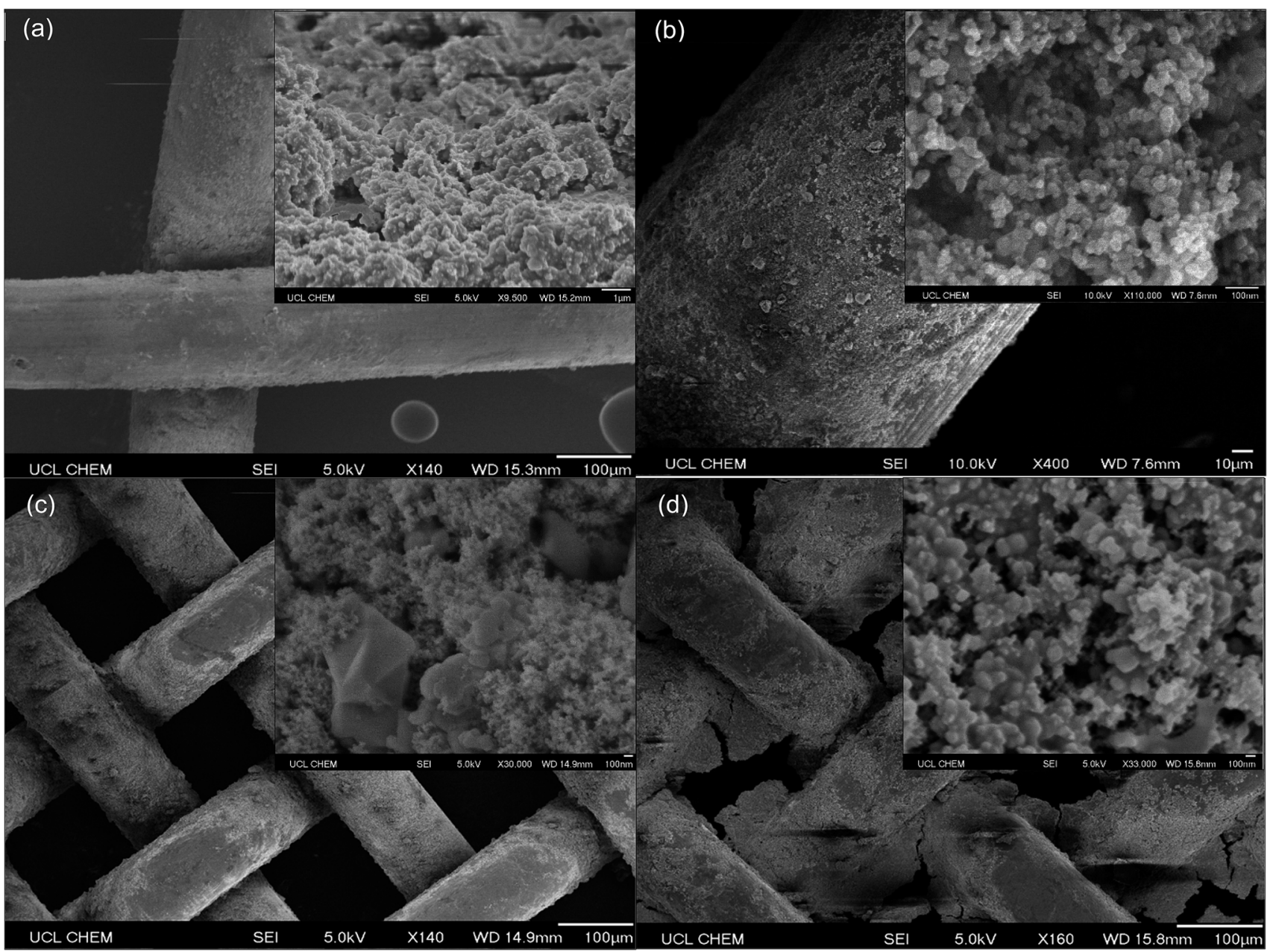

Fig. 5 SEM images of (a) coating D on a copper 30 mesh substrate $\left(\mathrm{SiO}_{2} 5-15 \mu \mathrm{m}\right.$ particles $(0.6 \mathrm{~g})$ with $\mathrm{TiO}_{2} 21 \mathrm{~nm}$ particles $(0.6 \mathrm{~g})$ in a $1: 9$ polymer mixture of Sylgard $\circledast 184$ and FAS), (b) coating D on a copper 60 mesh substrate $\left(\mathrm{SiO}_{2} 5-15 \mu \mathrm{m}\right.$ particles $(0.6 \mathrm{~g})$ with TiO $21 \mathrm{~nm}$ particles $(0.6 \mathrm{~g})$ in a $1: 9$ polymer mixture of Sylgard $₫ 184$ and FAS), (c) coating E on a copper 100 mesh substrate $\left(\mathrm{SiO}_{2} 5-15 \mu \mathrm{m}\right.$ particles $(0.6 \mathrm{~g})$ with $\mathrm{TiO}_{2}$ $21 \mathrm{~nm}$ particles $(0.6 \mathrm{~g})$ in a $0: 1$ polymer mixture of Sylgard ${ }^{\circledR} 184$ and FAS) and (d) coating $\mathrm{F}$ on a copper 100 mesh substrate (TiO $260-200 \mathrm{~nm}$ particles $(1.5 \mathrm{~g})$ with $\mathrm{TiO}_{2} 21 \mathrm{~nm}$ particles $(1.5 \mathrm{~g})$ in a $1: 4$ polymer mixture of Sylgard@ 184 and FAS).

copper 60 mesh substrates (95 $\pm 6 \%$ separation efficiency). Fig. 7 illustrates that all $\mathrm{H}-\mathrm{SiO}_{2} / \mathrm{TiO}_{2}$ particle combinations, A, B and $\mathrm{C}$, reached $100 \%$ separation efficiencies for $50 \%$ toluene$50 \%$ water solutions when coupled with their optimised Sylgard ${ }^{\circledR} 184$ : FAS polymer mixture. Subsequently, high separation efficiencies of $99 \pm 1 \%$ were achieved on dual scale $\mathrm{H}_{-} \mathrm{SiO}_{2}$ as well as $\mathrm{H}-\mathrm{SiO}_{2} / \mathrm{TiO}_{2}$ containing particle systems embedded in a 1 to 9 Sylgard ${ }^{\circledR} 184$ : FAS mixture when tested with $75 \%$ toluene-25\% water solutions. All particle and polymer mixture combinations had slightly reduced separation efficiencies for $25 \%$ toluene- $75 \%$ water solutions but remained $>90 \%$.

Final separation efficiencies on optimised coatings on copper 60 and 100 separation meshes have been recorded in Table S2. $\dagger$ Coating D $\left(\mathrm{SiO}_{2} 5-15 \mu \mathrm{m}\right.$ particles $(0.6 \mathrm{~g})$ with $\mathrm{TiO}_{2}$ $21 \mathrm{~nm}$ particles $(0.6 \mathrm{~g})$ in a $1: 9$ polymer mixture of Sylgard ${ }^{\circledR}$ 184 and FAS) coating $\mathrm{E}\left(\mathrm{SiO}_{2} 5-15 \mu \mathrm{m}\right.$ particles $(0.6 \mathrm{~g})$ with $\mathrm{TiO}_{2}$ $21 \mathrm{~nm}$ particles $(0.6 \mathrm{~g})$ in a $0: 1$ polymer mixture of Sylgard ${ }^{\circledR}$ 184 and FAS), coating $\mathrm{F}\left(\mathrm{TiO}_{2} 60-200 \mathrm{~nm}\right.$ particles $(1.5 \mathrm{~g})$ with $\mathrm{TiO}_{2} 21 \mathrm{~nm}$ particles $(1.5 \mathrm{~g})$ in a $1: 4$ polymer mixture of
Sylgard® 184 and FAS $)$ and coating $\mathrm{G}\left(\mathrm{SiO}_{2}{ }^{5-15} \mu \mathrm{m}\right.$ particles $(0.6 \mathrm{~g})$ with $\mathrm{TiO}_{2} 21 \mathrm{~nm}$ particles $(0.6 \mathrm{~g})$ in a $1: 4$ polymer mixture of Sylgard ${ }^{\circledR} 184$ and FAS) were functionally tested using various solvent systems. Table $\mathrm{S} 2 \uparrow$ documents solvent separation efficiencies for toluene-, hexane- and dichloromethanewater solutions along with associated errors.

The results indicated that coated copper 60 mesh substrates again were most likely to generate a favourable separation efficiency when compared to coated copper 100 mesh substrates. The larger pore diameter remained unblocked after coating with even the most viscous of polymer mixtures and therefore allowed toluene, hexane and dichloromethane to filter through the mesh; small pore 100 mesh substrate blockages most strongly inhibited the densest solvent, dichloromethane, from filtering through the device and consequently has not been featured in Table S2. $\dagger$ Despite the exceptional performance of all optimised coatings D-G, formulation $\mathrm{F}$ on 60 mesh substrates was an extremely effective separation coating with $100 \pm 0 \%, 85 \pm 0 \%$ and $97 \pm 0 \%$ efficiencies for toluene-, 


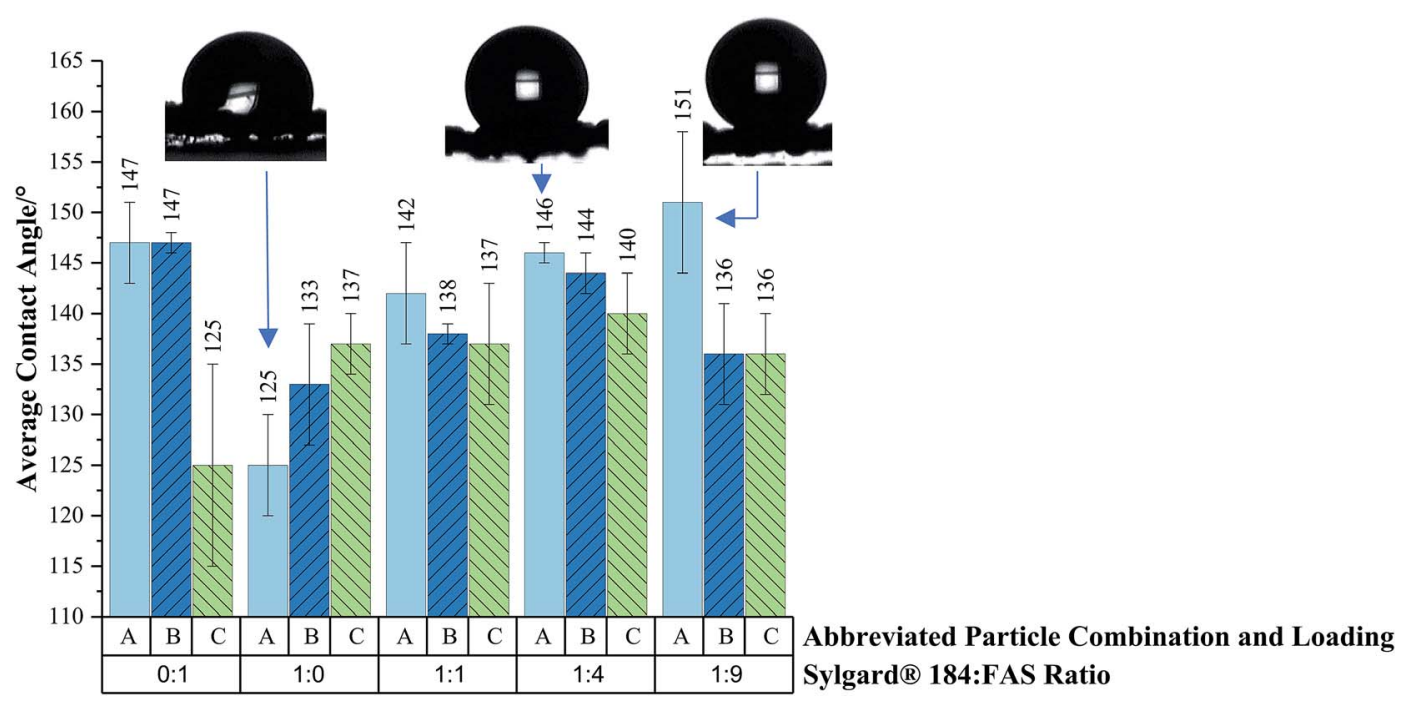

Fig. 6 Average water contact angle data on coatings containing various particle combinations and loadings embedded in a Sylgard $\AA^{8} 184$ and FAS polymer mixture. Abbreviated particle combination and loadings are as follows; A - $\mathrm{TiO}_{2} 60-200 \mathrm{~nm}$ particles $(0.6 \mathrm{~g})$ with $\mathrm{TiO} 221 \mathrm{~nm}$ particles $(0.6 \mathrm{~g}), \mathrm{B}-\mathrm{SiO}_{2} 5-15 \mu \mathrm{m}$ particles $(0.6 \mathrm{~g})$ with $\mathrm{TiO}_{2} 21 \mathrm{~nm}$ particles $(0.6 \mathrm{~g})$ and $\mathrm{C}-\mathrm{TiO}_{2} 60-200 \mathrm{~nm}$ particles $(0.6 \mathrm{~g})$ with $\mathrm{TiO} 221 \mathrm{~nm}$ particles $(0.6 \mathrm{~g})$. Each particle combination was embedded in $0: 1,1: 0,1: 1,1: 4$ and $1: 9$ Sylgard $184:$ FAS ratios. Coatings were applied to copper 60 mesh substrates prior to oven drying. Error bars show the maximum and minimum values obtained after three repeat readings.

hexane- and dichloromethane-water solutions respectively. The innately hydrophobic dual scale $\mathrm{TiO}_{2}$ particles embedded coating F's 1 : 4 Sylgard ${ }^{\circledR} 184$ : FAS mixture helped elevate the average water contact angle, $146 \pm 1^{\circ}$. This favourable particle combination coupled with the relatively high proportion of FAS in the coating elevated average contact angles and improved separation potential. Various other separation materials that used longer more elaborate fabrication procedures have been well documented over recent years. Separation efficiencies $\sim$ $95 \%$ were achieved but the vast number of readily available oils/ solvents and the absence of a standardized separation method makes it difficult to directly contrast like results from across the field. ${ }^{36-41}$

Due to the adhesive properties of Sylgard ${ }^{\circledR} 184$, optimised coatings D, F and G remained comparably functional, within the original error limits represented in Fig. 6, after 3 washseparation-wash cycles and the Scotch tape test. Fig. 8 displays the water contact angle image post separation testing of coating D; unaltered water repellency further supports coating robustness. The $1: 9$ and $1: 4$ Sylgard ${ }^{\circledR} 184:$ FAS ratios provided the

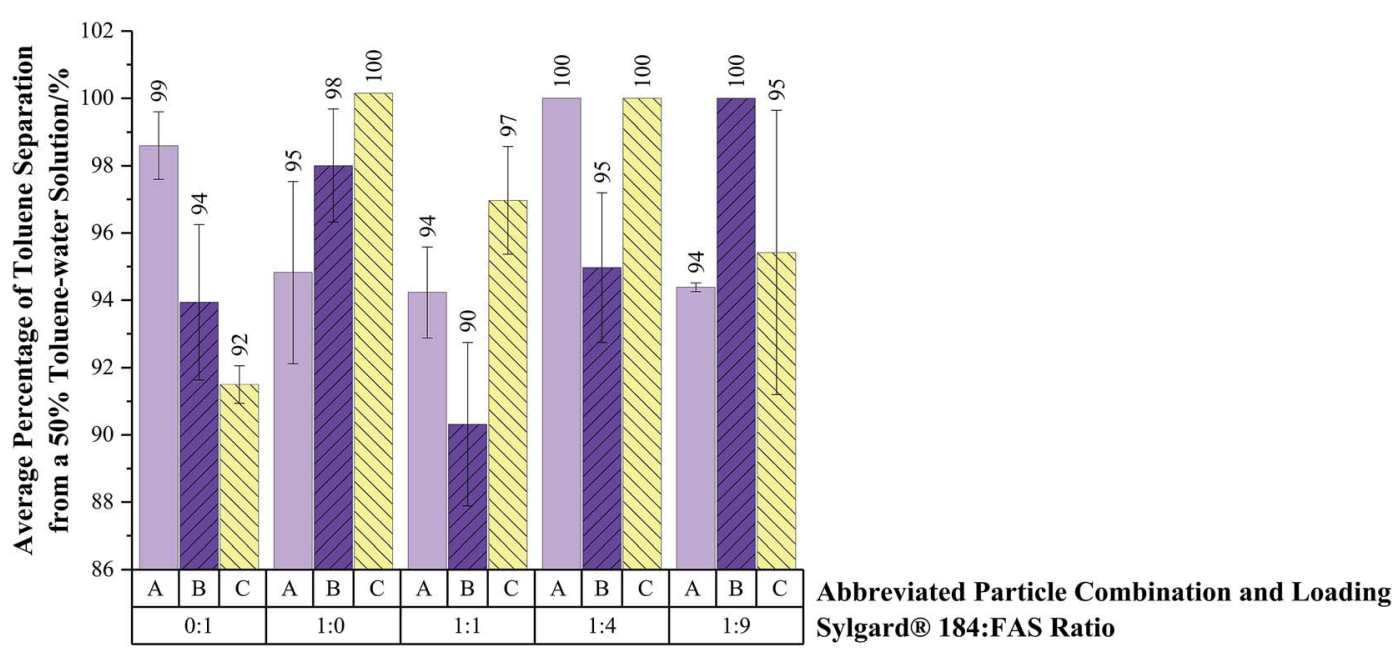

Fig. 7 Average percentage of toluene separated from a 50\% toluene-water solution on coatings containing various particle combinations and loadings embedded in a Sylgard ${ }^{\circledR} 184$ and FAS polymer mixture. Abbreviated particle combination and loadings are as follows; $\mathrm{A}-\mathrm{TiO} \mathrm{O}_{2} 60-$ $200 \mathrm{~nm}$ particles $(0.6 \mathrm{~g})$ with $\mathrm{TiO}_{2} 21 \mathrm{~nm}$ particles $(0.6 \mathrm{~g}), \mathrm{B}-\mathrm{SiO}_{2} 5-15 \mu \mathrm{m}$ particles $(0.6 \mathrm{~g})$ with $\mathrm{TiO}_{2} 21 \mathrm{~nm}$ particles $(0.6 \mathrm{~g})$ and C $-\mathrm{TiO}_{2} 60-$ $200 \mathrm{~nm}$ particles $(0.6 \mathrm{~g})$ with $\mathrm{TiO}_{2} 21 \mathrm{~nm}$ particles $(0.6 \mathrm{~g})$. Each particle combination was embedded in $0: 1,1: 0,1: 1,1: 4$ and $1: 9$ Sylgard 184 : FAS ratios. Coatings were applied to copper 60 mesh substrates prior to oven drying. Error bars show the maximum and minimum values obtained after three repeat readings. 


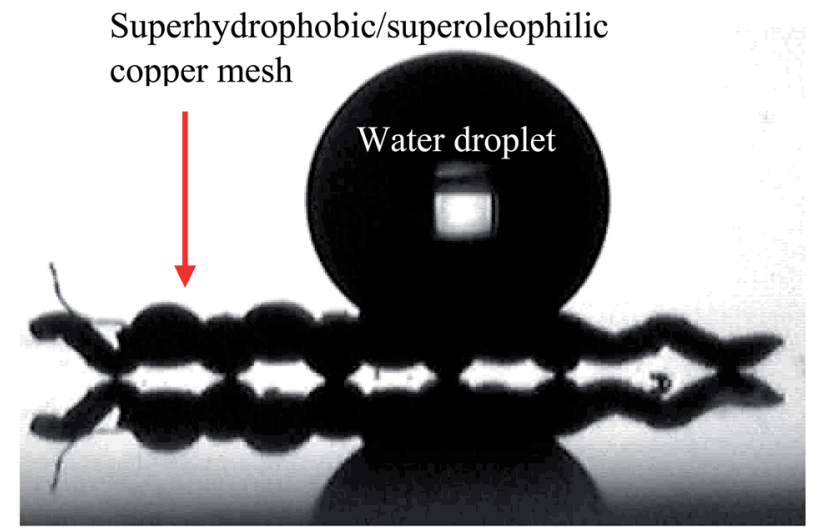

Fig. 8 Water droplet on a copper 60 mesh substrate with a coating $D$ surface $\left(\mathrm{SiO}_{2} 5-15 \mu \mathrm{m}\right.$ particles $(0.6 \mathrm{~g})$ with $\mathrm{TiO}_{2} 21 \mathrm{~nm}$ particles $(0.6 \mathrm{~g})$ in a $1: 9$ polymer mixture of Sylgard $® 184$ and FAS). Image was recorded post separation functional testing.

ideal particle embedded polymer systems to preserve surface morphology and pore structures (copper 60 mesh substrates), establish preferred wettabilities and achieve surface durability.

The most favorable separation meshes were identified as a result of ensuring surface morphologies and open pore structures were preserved whilst tailoring the surface energy to reside between that of oil and water (approximately between 30 $\mathrm{mN} \mathrm{m}^{-1}$ and $\left.70 \mathrm{mN} \mathrm{m}^{-1}\right) .{ }^{42}$ Trends were identified that indicated solvent density had a significant part to play. For example, copper 100 mesh separation rates were substantially higher using toluene-water solutions as opposed to hexane for identical surface coatings. This was attributed to toluene's increased density of $865 \mathrm{~kg} \mathrm{~m}^{-3},{ }^{43}$ as opposed to $672 \mathrm{~kg} \mathrm{~m}^{-3}$ for hexane. ${ }^{44}$ A denser solvent was able to more quickly permeate a mesh substrate when originally mixed with water.

\section{Conclusion}

A facile route to fabricate a superior (super)hydrophobic and oleophilic separation surface was devised throughout this research. Hierarchical surface roughening in combination with silicon-based polymers generated water repellent coatings with oil-loving properties. Numerous different combinations and concentrations of dual scale $\mathrm{TiO}_{2}$ and/or hydrophobic-SiO${ }_{2}(\mathrm{H}$ $\mathrm{SiO}_{2}$ ) particles in varying Sylgard ${ }^{\circledR} 184$ : FAS polymer ratio mixtures were explored in order to enhance surface wettabilities. Average water contact angles were linked to improved solvent separation efficiencies, which, in turn, were most favourable on samples with higher quantities of the fluorinerich fluoroalkylsilane, FAS, polymer. For example, coating F's dual scale $\mathrm{TiO}_{2}$ particle system embedded in a $1: 4$ Sylgard ${ }^{\circledR}$ 184 : FAS polymer mixture was applied to copper 60 mesh substrates (pore diameter of $250 \mu \mathrm{m}$ ). The resulting device was highly functional with $100 \pm 0 \%, 85 \pm 0 \%$ and $97 \pm 0 \%$ separation efficiencies for toluene-, hexane- and dichloromethanewater solutions respectively. A trade-off between the highly adhesive and durable Sylgard® 184 polymer and the low surface energy FAS, in a $1: 4$ ratio, afforded robust separation coatings that showed no deviation in functionality after 3 wash-separation-wash cycles nor after the Scotch tape test.

\section{Conflicts of interest}

There are no conflicts to declare.

\section{Acknowledgements}

The authors wish to thank Innovate UK (102541) and EPSRC for grant EP/N510051 and for studentship funding (FLH) through the $\mathrm{M}^{3} \mathrm{~S}$ Doctoral Training Centre (grant EP/G036675) and Akzonobel for financially supporting this project.

\section{References}

1 J. Coca-Prados and G. Gutiérrez-Cervelló, Water Purification and Management, Springer Netherlands, Dordrecht, 2011.

2 S. P. Zhu and D. Strunin, A Numerical Model for the Confinement of Oil Spill with Floating Booms, Spill Sci. Technol. Bull., 2002, 7, 249-255.

3 Statistics - ITOPF, available from: http:/www.itopf.com/ knowledge-resources/data-statistics/statistics/.

4 G. McHale, N. J. Shirtcliffe and M. I. Newton, Contact-angle hysteresis on super-hydrophobic surfaces, Langmuir, 2004, 20, 10146-10149.

5 A. Marmur, Solid-surface characterization by wetting, Annu. Rev. Mater. Res., 2009, 39, 473-489.

6 A. M. Peters, C. Pirat, M. Sbragaglia, B. M. Borkent, M. Wessling, D. Lohse and R. G. H. Lammertink, CassieBaxter to Wenzel state wetting transition: scaling of the front velocity, Eur. Phys. J. E: Soft Matter Biol. Phys., 2009, 29, 391-397.

7 S. M. Lee, C. Y. Park, S. Il Bae, J. S. Go, B. Shin and J. S. Ko, Surface Wettability in Terms of the Height and Depression of Diverse Microstructures and Their Sizes, Jpn. J. Appl. Phys., 2009, 48, 955041-955045.

$8 \mathrm{~J}$. Bico, U. Thiele and D. Quéré, Wetting of Textured Surfaces, Colloids Surf., A, 2002, 206, 41-46.

9 C. R. Crick and I. P. Parkin, Superhydrophobic polymer films via aerosol assisted deposition - taking a leaf out of nature's book, Thin Solid Films, 2010, 518, 4328-4335.

10 C. R. Crick and I. P. Parkin, A single step route to superhydrophobic surfaces through aerosol assisted deposition of rough polymer surfaces: duplicating the lotus effect, J. Mater. Chem., 2009, 19, 1074-1076.

11 S. Li, K. Page, S. Sathasivam, F. Heale, G. He, Y. Lu, Y. Lai, G. Chen, C. J. Carmalt and I. P. Parkin, Efficiently texturing hierarchical superhydrophobic fluoride-free translucent films by AACVD with excellent durability and self-cleaning ability, J. Mater. Chem. A, 2018, 6, 17633-17641.

12 R. J. Good, Contact angle, wetting, and adhesion: a critical review, J. Adhes. Sci. Technol., 1992, 6, 1269-1302.

13 A. W. Adamson, Physical chemistry of surfaces, John Wiley \& Sons, New York, 5th edn, 1990.

14 A. K. An, J. Guo, E.-J. Lee, S. Jeong, Y. Zhao, Z. Wang and T. Leiknes, PDMS/PVDF hybrid electrospun membrane 
with superhydrophobic property and drop impact dynamics for dyeing wastewater treatment using membrane distillation, J. Membr. Sci., 2017, 525, 57-67.

15 C. Yang, B. Li, M. Ren and H. Fu, Kinetics of wetting of liquid on a solid surface, Sci. China, Ser. B: Chem., 2009, 52, 868873.

16 Attension Applications - Biolin Scientific, available from: http:/www.biolinscientific.com/zafepress.php?url=/pdf/ Attension/ApplicationNotes/AT_AN_9_dynamic.pdf.

17 T. S. Meiron, A. Marmur and I. S. Saguy, Contact angle measurement on rough surfaces, J. Colloid Interface Sci., 2004, 274, 637-644.

18 J. E. George, V. R. M. Rodrigues, D. Mathur, S. Chidangil and S. D. George, Self-cleaning superhydrophobic surfaces with underwater superaerophobicity, Mater. Des., 2016, 100, 8-18.

19 T. Darmanin and F. Guittard, Superhydrophobic and superoleophobic properties in nature, Mater. Today, 2015, 18, 273-285.

20 Z. Xue, Y. Cao, N. Liu, L. Feng and L. Jiang, Special wettable materials for oil/water separation, J. Mater. Chem. A, 2014, 2, 2445-2460.

21 C. Wang, T. Yao, J. Wu, C. Ma, Z. Fan, Z. Wang, Y. Cheng, Q. Lin and B. Yang, Facile Approach in Fabricating Superhydrophobic and Superoleophilic Surface for Oil and Water Mixture Separation, ACS Appl. Mater. Interfaces, 2009, 1, 2613-2617.

22 Q. Pan, M. Wang and H. Wang, Separating a small amount of water and hydrophobic solvents by novel superhydrophobic copper meshes, Appl. Surf. Sci., 2008, 254, 6002-6006.

23 C. Lee and S. Baik, Vertically-aligned carbon nano-tube membrane filters with superhydrophobicity and superoleophilicity, Carbon, 2010, 48, 2192-2197.

24 J. Li, R. Kag, X. Tang, H. She, Y. Yang and F. Zha, Superhydrophobic meshes that can repel hot water and strong corrosive liquids used for efficient gravity-driven oil/ water separation, Nanoscale, 2016, 8, 7638-7645.

25 D. D. La, T. A. Nguyen, S. Lee, J. W. Kim and Y. S. Kim, A stable superhydrophobic and superoleophilic $\mathrm{Cu}$ meshed based on sopper hydroxide nanoneedle arrays, Appl. Surf. Sci., 2011, 257, 5705-5710.

26 J. Wu, J. Chen, K. Qasim, J. Xia, W. Lei and B. Wang, A hierarchical mesh film with superhydrophobic and superoleophilic properties for oil and water separation, $J$. Chem. Technol. Biotechnol., 2012, 87, 427-430.

27 C. W. Tu, C. H. Tsai, C. F. Wang, S. W. Kuo and F. C. Chang, Fabrication of Superhydrophobic and Superoleophilic Polystyrene Surfaces by a Facile One-Step Method, Macromol. Rapid Commun., 2007, 28, 2262-2266.

28 L. Wang, S. Yang, J. Wang, C. Wang and L. Chen, Fabrication of superhydrophobic TPU film for oil-water separation based on electrospinning route, Mater. Lett., 2011, 65, 869-872.

29 R. Kumar Gupta, G. J. Dunderdale, M. W. England and A. Hozumi, J. Mater. Chem. A, 2018, 5, 16025-16058.
30 J. Li, C. Xu, C. Guo, H. Tian, F. Zha and L. Guo, J. Mater. Chem. A, 2018, 6, 223-230.

31 C. Sleigh, A. P. Pijpers, A. Jaspers, B. Coussens and R. J. Meier, On the determination of atomic charge via ESCA including application to organometallics, J. Electron Spectrosc. Relat. Phenom., 1996, 77, 41-57.

32 J. L. Sullivan, S. O. Saied and I. Bertoti, Effect of ion and neutral sputtering on single crystal $\mathrm{TiO}_{2}$, Vacuum, 1991, 42, 1203-1208.

33 A. Sabata, Plasma-polymerized films of trimethylsilane deposited on cold-rolled steel substrates. Part 1. characterization by XPS, AES and TOF-SIMS, Surf. Interface Anal., 1993, 20, 845-859.

34 M. H. Kibel, X-ray photoelectron spectroscopy study of optical waveguide glasses, Surf. Interface Anal., 1996, 24, 605-610.

35 D. Lin-Vien, N. B. Colthup, W. G. Fateley and J. G. Grasselli, The Handbook of Infrared and Raman Characteristic Frequencies of Organic Molecules, Elsevier, 1991.

36 Z. Xue, S. Wang, L. Lin, L. Chen, M. Liu, L. Feng and L. Jiang, A Novel Superhydrophilic and Underwater Superoleophobic Hydrogel-Coated Mesh for Oil/Water Separation, Adv. Mater., 2011, 23, 4270-4273.

37 L. Zhang, Y. Zhong, D. Cha and P. Wang, A self-cleaning underwater superoleophobic mesh for oil-water separation, Sci. Rep., 2013, 3, 23260-23265.

38 X. Wang, J. Yu, G. Sun and B. Ding, Electrospun nanofibrous materials: a versatile medium for effective oil/water separation, Mater. Today, 2015, 19, 403-414.

39 J. Zhang and S. Seeger, Polyester Materials with Superwetting Silicone Nanofilaments for Oil/Water Separation and Selective Oil Absorption, Adv. Funct. Mater., 2011, 21, 46994704 .

40 K. Jayaramulu, K. K. R. Datta, C. Rösler, M. Petr, M. Otyepka, R. Zboril and R. A. Fischer, Biomimetic Superhydrophobic/ Superoleophilic Highly Fluorinated Graphene Oxide and ZIF-8 Composites for Oil-Water Separation, Angew. Chem., Int. Ed. Engl., 2016, 55, 1178-1182.

41 X. Wang, S. Xu, Y. Tan, J. Du and J. Wang, Synthesis and characterization of a porous and hydrophobic cellulose based composite for efficient and fast oil-water separation, Carbohydr. Polym., 2016, 140, 188-194.

42 T. Ogawa, B. Ding, Y. Sone and S. Shiratori, Superhydrophobic surfaces of layer-by-layer structures film coated electrospun nanofibrous membranes, Nanotechnology, 2007, 18, 1656071-1656078.

$43 \mathrm{Y}$. Chen and H. Kim, Preparation of superhydrophobic membranes by electrospinning of fluorinated silane functionalized poly(vinylidene fluoride), Appl. Surf. Sci., 2009, 255, 7073-7077.

44 B. Liu, Y. He, Y. Fan and X. Wang, Fabricating Superhydrophobic Lotus-Leaf-Like Surfaces through SoftLithographic Imprinting, Macromol. Rapid Commun., 2006, 27, 1859-1864. 